\title{
Antioxidant Activities of Bingöl Royal Jelly on SH-SY5Y Cells
}

\section{Eray Çalışkan ${ }^{1}$, Adnan Ayna ${ }^{2}$, Abdullah Tunç ${ }^{3}$, Sedanur Özbolat ${ }^{4}$, Aydın Şükrü Bengü 5 , Gürkan Aykutoğlu' ${ }^{6}$, Mehmet Çiftci ${ }^{7}$, Ekrem Darendelioğlü*}

${ }^{1}$ Bingol University Faculty of Art and Sciences, Chemistry, Bingol 12000, Turkey, orcid.org/0000-0003-2399-4100

2Bingol University Faculty of Art and Sciences, Chemistry, Bingol 12000, Turkey, orcid.org/0000-0001-6801-6242

${ }^{3}$ Bingol University Faculty of Health Sciences, Occupational Health and Safety, Bingol 12000, Turkey, orcid.org/0000-0002-2378-5897

${ }^{4}$ Bingol University Faculty of Art and Sciences, Chemistry, Bingol 12000, Turkey, orcid.org/0000-0001-7597-5388

${ }^{5}$ Bingol University Vocational School of Health Services, Medical Sevices and Techniques, Bingol 12000, Turkey, orcid.org/0000-0002-4158-5002

${ }^{6}$ Bingol University Faculty of Art and Sciences, Molecular Biology and Genetic, Bingol 12000, Turkey, orcid.org/0000-0002-5225-9845

${ }^{7}$ Bingol University Faculty of Art and Sciences, Chemistry, Bingol 12000, Turkey, orcid.org/0000-0003-4971-4242

${ }^{8}$ Bingol University Faculty of Art and Sciences, Molecular Biology and Genetic, Bingol 12000, Turkey,

orcid.org/0000-0002-0630-4086

*Corresponding author: edarendelioglu@bingol.edu.tr

Received: 11 October 2021, Accept: 06 November 2021, Published Online: 01 December 2021

\begin{abstract}
Royal Jelly is a bee product with high protein content is a unique nutrient for the queen honeybee. It leads to a substantial elongation of the lifetime of the queen in comparison to the worker honeybees via anti-inflammatory, anti-oxidant, anti-cancer and anti-microbial properties. Flavonoids naturally have reported to have anticancer activities thanks to their potent antioxidant activity. The antioxidant activity of RJ is attributed to its rich flavonoid content however anti-oxidant activities of the Bingöl RJ has yet to be explored in detail. The goal of the current study was to investigate the antioxidant activities of Bingöl RJ on SH-SY5Y neuroblastoma cells. The results of our study revealed that Bingöl RJ at a concentration of $0.3 \mathrm{mg} / \mathrm{ml}$ significantly augmented ROS level in SH-SY5Y cells while $0.5 \mathrm{mg} / \mathrm{ml}$ of RJ had almost no effect on ROS levels. The levels of malondialdehyde in SH-SY5Y cells considerably increased in the presence of $0.3 \mathrm{mg} / \mathrm{ml} \mathrm{RJ}$ while $0.5 \mathrm{mg} / \mathrm{ml} \mathrm{RJ}$ had no significant impact on MDA levels in SH-SY5Y cells. The results showed that RJ treatment $0.3 \mathrm{mg} / \mathrm{ml}$ ) significantly lowered the activities of SOD and CAT activity while $0.5 \mathrm{mg} / \mathrm{ml}$ of RJ had negligible effect indicating that RJ could protect the cell membranes from radical mediated cell injuries.
\end{abstract}

Key words: Antioxidant, Catalase, Flavonoids, Royal Jelly, SH-SY5Y 


\section{Introduction}

Royal jelly is a yellowish, gelatinous bee product which is secreted by the hypopharyngal and mandibullar glands of worker honeybees and strongly affects the larval growth in the hive that includes the queen bee (Hu et al., 2019; Gismondi et al., 2017). RJ is predominantly composed of water (60\% to $70 \%$ ) carbohydrates (11\% to $23 \%$ ), peptides, proteins ( $9 \%$ to $18 \%$ ), fatty acids, lipids ( $4 \%$ to $8 \%$ ), vitamins and mineral salts (Melliou and Chinou, 2005, Ramadan and Al-Ghamdi, 2012; Malka et al., 2009; Fratini et al., 2016). Royal jelly have been shown to have many biological activities that include antibacterial (Ramanathan et al., 2018; Fujiwara et al., 1990), anti-inflammatory (Yanagita et al., 2011), vasodilative and hypotensive (Pan et al., 2019), disinfectant, antioxidant (Park et al., 2019), and antitumor activities. These activities are predominantly credited to its flavonoid content.

Flavonoid has been reported to exhibit a wide range of biological activities, including anti-bacterial, antiviral, anti-inflammatory, anti-allergic, anticancer and vasodilatory actions (Ayna et al., 2020; Abotaleb et al., 2019; Yin et al., 2019). The flavonoids that include acacetin, apigenin, chrysin, kaempherol, pinocembrin, hesperidin and quercetin contribute to its antioxidant activity (Kocot et al., 2018; Pasupuleti et al., 2017; Viuda-Martos et al., 2008). Flavonoids naturally has reported to have anticancer activities thanks to their potent antioxidant activity in conjunction with their ability to impact cell proliferation and induction of apoptosis as reviewed in (Premratanachai and Chanchao, 2014; Pasupuleti et al., 2017).

Neuroblastoma is the most commonly diagnosed cancer during early years of childhood. Despite being accounted for the improperly high despair and fetality amongst the childhood cancers, neuroblastoma has one of the highest casual and complete regression rates (Maris, 2010). The biological activities of 6 dissimilar RJs on the growth of immortalized murine myoblasts, human prostate cancer and human neuroblastoma have been explored in a different study (Gismondi et al., 2017). However, the antioxidant activities of Bingöl Royal Jelly has yet to be studied on SH-SY5Y neuroblastoma cells. This study was designed to explore the antioxidant activities of Bingöl RJ on SH-SY5Y neuroblastoma cells.

\section{Material and Methods}

\subsection{Cell culture}

SH-SY5Y cells were maintained at $37^{\circ} \mathrm{C}$ in a humidified $5 \% \mathrm{CO}_{2}$, in Dulbecco's Modified Eagle Medium completed with $10 \% \mathrm{FBS}, 1 \%$ penicillin-streptomycin in $25 \mathrm{~cm}^{2}$ cell culture flasks for $24 \mathrm{~h}$. Following day, the cells were exposed to different concentrations of RJ between 0.15 and $30 \mathrm{mg} / \mathrm{ml}$ for $24 \mathrm{~h}$. The control cell was grown in the same medium without RJ.

\subsection{Detection of intracellular reactive oxygen species (ROS) level}

Cellular ROS creation was evaluated by use of DCFH-DA assay kit purchased from Abcam, MA, USA, as previously defined (Ayna, 2021, Özbolat and Ayna, 2021). Cells were treated as given in cell culture. Following treatment and growing the cells, $1 \times 10^{6} \mathrm{SH}-\mathrm{SY} 5 \mathrm{Y}$ cells were collected and incubated for $1 \mathrm{~h}$ at $37^{\circ} \mathrm{C}$ in the presence of $2 \mu \mathrm{M} \mathrm{DCFH}-\mathrm{DA}$ and fluorescence was measured. 


\subsection{Examination of MDA level}

For evaluating malandialdehyde (MDA) level in RJ exposed SH-SY5Y cells, a minor adjustment of previously published protocol was utilised (Ayna, 2020). SH-SY5Y were grown as described in cell culture. The cells were scraped and centrifugation was performed for five minutes at $3000 \mathrm{rpm}$. Later, the cell suspensions were treated with LPO asay cokctail containing $70 \% \mathrm{w} / \mathrm{v}$ trichloroacetic acid and $1 \mathrm{ml}$ of $0.8 \% \mathrm{w} / \mathrm{v}$ thiabarbituric acid and was incubated for half an hour at $95{ }^{\circ} \mathrm{C}$. Subsequent to that, the mixture was incubated on ice for five minutes and afterwards, the suspension of the cells were centrifuged at $15000 \mathrm{rpm}$ for $10 \mathrm{~min}$. The absorbance measurement of the supernatant was taken at $532 \mathrm{~nm}$.

\subsection{Measurement of CAT and SOD activity}

The cells were treated as stated in cell culture. The assays were performed following the manufacturer's instructions provided with the catalase Assay kit (Elabscience), SOD Assay ELISA kit (SunRed).

\subsection{Statistical analysis}

All of the experimentation procedures were rerun for at least three replicates. The data was statistically analysed and the data groups (comparable) were evaluated by GraphPed Prism 5 by one-way ANOVA NemwanKeuls PostHoc Test; $p<0.05$ was considered as significant.

\section{Results and Discussion}

The effects of RJ treatment on ROS generation in SH-SY5Y cells were also examined. The results demonstrated that RJ at $0.3 \mathrm{mg} / \mathrm{ml}$ dose remarkably augmented ROS level in SH-SY5Y cells while $0.5 \mathrm{mg} / \mathrm{ml}$ of RJ had almost no effect on ROS levels (Fig.1).

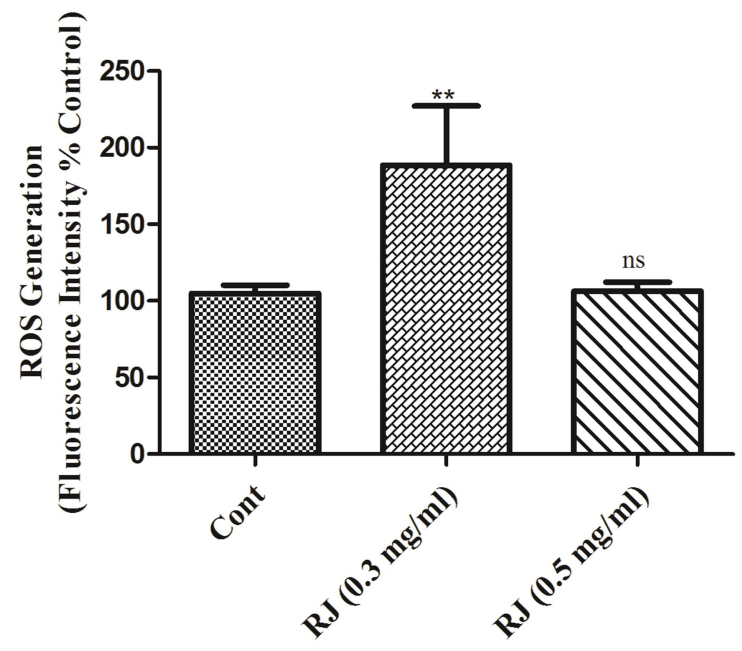

Figure 1. Effects of Bingöl RJ on levels of ROS in SH-SY5Y cells.

To understand whether RJ contributed to the apoptosis of SH-SY5Y, LPO assay was performed by 0.3 and $0.5 \mathrm{mg} / \mathrm{mL}$ to detect MDA levels. As shown in Figure 2, the level of MDA in SH-SY5Y cells remarkably 
increased in the presence of $0.3 \mathrm{mg} / \mathrm{ml} \mathrm{RJ}$ while $0.5 \mathrm{mg} / \mathrm{ml} \mathrm{RJ}$ had no significant impact on MDA levels in SHSY5Y cells.

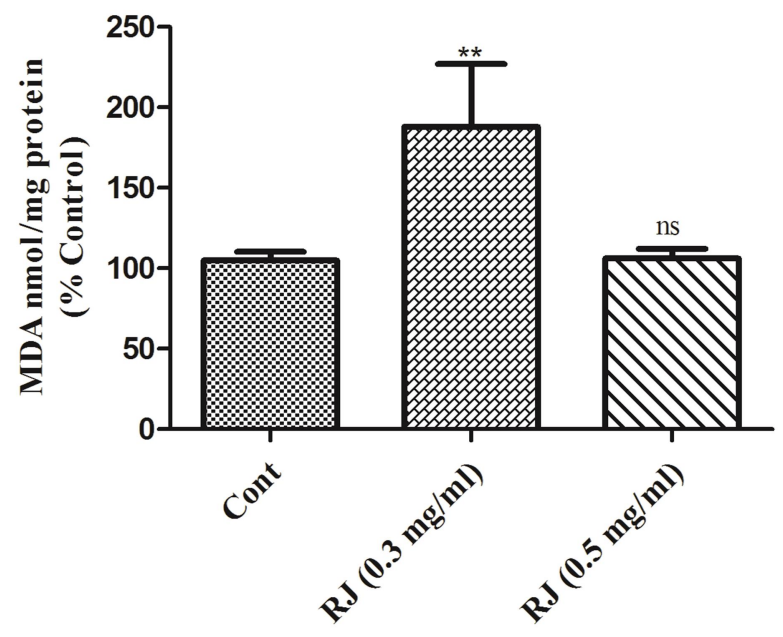

Figure 2. Effects of Bingöl RJ on levels of LPO in SH-SY5Y cells.

The antioxidant effects of RJ in neuroblastoma cells were also extensively examined within this study. The results showed that RJ treatment $(0.3 \mathrm{mg} / \mathrm{ml}$ ) significantly lowered the activities of SOD (Fig. 3 ) and CAT (Fig 4) activity while $0.5 \mathrm{mg} / \mathrm{ml}$ of RJ had negligible effect indicating that Bingöl RJ could protect the cell membranes from radical mediated cell injuries.

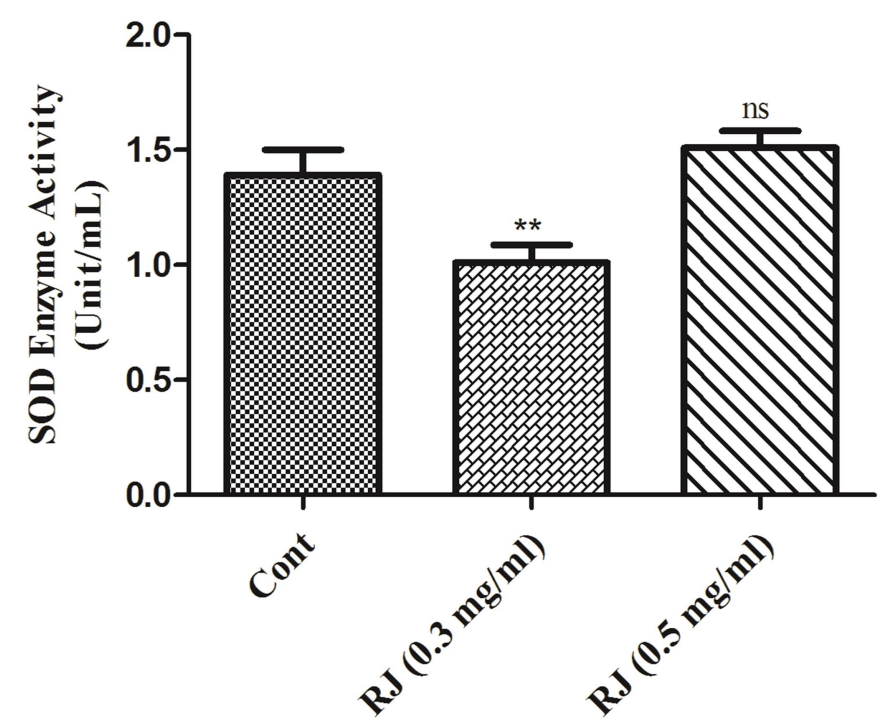

Figure 3. Effects of Bingöl RJ on the activity of SOD in SH-SY5Y cells. 


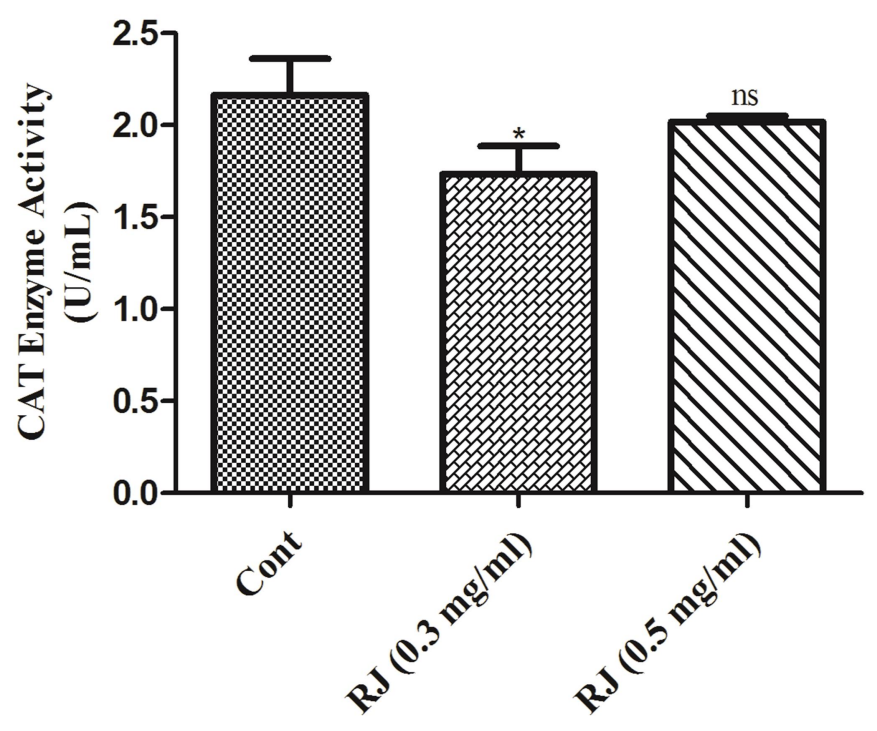

Figure 4. Effects of Bingöl RJ on activity of catalase in SH-SY5Y cells.

$\mathrm{RJ}$ is a bee product with high protein content is a unique nutrient for the queen honey bee. It leads to a substantial elongation of the lifetime of the queen in comparison to the worker honey bees via anti-inflammatory, oxidant, -cancer and -microbial properties (Fratini et al., 2016; Liu et al., 2008; Nakajima et al., 2009; Kolayli et al., 2016; Silici, 2019). Therefore, RJ has been extensively used in cosmetic and food industries throughout the world (Hameed et al., 2019; Yeung and Argüelles, 2019). Additionally, in vitro and in vivo studies has shown that RJ decreases cell viability and modulates apoptotic pathway in several kinds of malignant cells and impacts the generation of anti-oxidants and the expression of cancer-associated compounds particularly in treated patients with anti-cancer agents (Miyata and Sakai, 2018). Therefore, RJ is considered to have anti-cancer effects on tumour growing and display protecting roles towards drug-stimulated toxicity. RJ have also been verified to be beneficial for inhibition of side effects, the preservation of the quality of life throughout treatment and the enhancement of diagnosis in cancer patients (Porta et al., 2014). To comprehend the machineries of the valuable impacts of RJ, awareness of the alterations stimulated at the biomolecular levels by RJ with regard to cell proliferation, oxidative damage and other cancer-associated elements is reviewed to be indispensable (Miyata and Sakai, 2018). Thus, in this study, we have examined the anti-oxidant effects of RJ against neuroblastoma cell line SH-SY5Y and mechanisms underlying its effects.

Neuroblastoma, developmental tumour of infants, is the most commonly diagnosed cancer during early years of childhood. Despite being accounted for the improperly high despair and fetality amongst the childhood cancers (accounts for $\sim 13 \%$ of all pediatric cancer mortality), neuroblastoma has one of the highest casual and complete regression rates (Maris, 2010; Tartik et al., 2016; Du et al., 2017; Jacquemin et al., 2015).

Supposing that the amount of the ROS created within the cell is excessive to overthrown endogenous anti-oxidant respond, irreversible oxidative injuries to the DNA and RNA, fats, and amino acid (proteins) could result in genetic and/or epi-genetic changes causing a dysregulation in oncogenes and key tumor suppressor 
genes.Therefore, oxidative damages lead alterations in the expression of the genes, proliferation of the cell and programed cell death and has an important function in progression and initiation of the tumor (Jelic et al., 2021). Oxidative injuries to the lipids results in lipid peroxidation that primarily located in the membranes causing a loss in membrane integrity. Their reactive final substances could then harm other biomolecules. During their exposure to low lipid peroxidation, cellular defensce mechanisms resulted in adaption, whereas a high concentrayion of MDA (a marker of LPO) triggers programmed cell death or activation of necrosis. Amongst several types of aldehydes that could be generated as secondary products during lipid peroxidation, MDA is the most extensively researched (Ayala et al., 2014). For understanding whether the cellular processes of RJ treatment on cell survival can be related to specific induction patterns of ROS and LPO, we demonstrate that RJ resulted in a rise in ROS and LPO levels. The effects of several different types and groups of antioxidants on several different cell lines and animals model have been well investigated to date. These antioxidants have also well studied to understand their roles in the cure of several diseases led by oxidative injuries (Ighodaro et al., 2018). In a study, our colleagues have found that that chysin increased lead acetate-induced catalase and superoxide dismutase activities (Bengu et al., 2021). In a different study, another antioxidant molecule, hesperidin, increased $\mathrm{NaF}$ induced catalase and superoxide dismutase activities (Caglayan et al., 2021). In our study, the catalytic activities of CAT and SOD were considerably reduced in RJ-exposed neuron cells. Bingöl RJ was also shown to increase levels of MDA and ROS on SH-SY5Y cells indicating that RJ could protect the cell membranes from radical mediated cell injuries. All of these findings reveal antioxidant properties of Bingöl RJ.

\section{Acknowledgement}

This study was financially supported by Presidency of The Republic of Turkey Strategy and Budget Presidency (Former Development Ministry), coordinated by Council of Higher Education and organized by The Scientific Research Projects Coordination Unit of Bingöl University (Project Number: 2017K124000-BÜBAPPiKOM-Arı.2018.001).

\section{Conflict of interest}

The author declares that there is no conflict of interests

\section{References}

Abotaleb, M., Samuel, S. M., Varghese, E., Varghese, S., Kubatka, P., Liskova, A., \& Büsselberg, D. (2019). Flavonoids in cancer and apoptosis. Cancers, 11(1), 28. https://doi.org/10.3390/cancers11010028

Ayala, A., Muñoz, M. F., \& Argüelles, S. (2014). Lipid peroxidation: production, metabolism, and signaling mechanisms of malondialdehyde and 4-hydroxy-2-nonenal. Oxidative Medicine and Cellular Longevity, 36043.

Ayna, A. (2020). Apoptotic effects of beta-carotene, alpha-tocopherol and ascorbic acid on PC-3 prostate cancer cells. Hacettepe Journal of Biology and Chemistry, 48(3), 211-218. 
Ayna, A. (2021). Caffeic acid prevents hydrogen peroxide-induced oxidative damage in SH-SY5Y cell line through mitigation of oxidative stress and apoptosis. Bratislavske Lekarske Listy, 122(2), 120-124.

Ayna, A., Özbolat, S. N., \& Darendelioglu, E. (2020). Quercetin, chrysin, caffeic acid and ferulic acid ameliorate cyclophosphamide-induced toxicities in SH-SY5Y cells. Molecular Biology Reports, 47(11), 8535-8543.

Caglayan, C., Kandemir, F. M., Darendelioğlu, E., Küçükler, S., \& Ayna, A. (2021). Hesperidin protects liver and kidney against sodium fluoride-induced toxicity through anti-apoptotic and anti-autophagic mechanisms. Life Sciences, 119730.

Chan, W. H., Wu, C. C., \& Yu, J. S. (2003). Curcumin inhibits UV irradiation-induced oxidative stress and apoptotic biochemical changes in human epidermoid carcinoma A431 cells. Journal of Cellular Biochemistry, 90(2), 327-338.

Du, X., Shi, Z., Peng, Z., Zhao, C., Zhang, Y., Wang, Z., \& Li, X. (2017). Acetoacetate induces hepatocytes apoptosis by the ROS-mediated MAPKs pathway in ketotic cows. Journal of Cellular Physiology, 232(12), 3296-3308.

Fratini, F., Cilia, G., Mancini, S., \& Felicioli, A. (2016). Royal Jelly: An ancient remedy with remarkable antibacterial properties. Microbiological Research, 192, 130-141.

Fujiwara, S., Imai, J., Fujiwara, M., Yaeshima, T., Kawashima, T., \& Kobayashi, K. (1990). A potent antibacterial protein in royal jelly. Purification and determination of the primary structure of royalisin. Journal of Biological Chemistry, 265(19), 11333-11337.

Gismondi, A., Trionfera, E., Canuti, L., Di Marco, G., \& Canini, A. (2017). Royal jelly lipophilic fraction induces antiproliferative effects on SH-SY5Y human neuroblastoma cells. Oncology Reports, 38(3), 1833-1844.

Hameed, A., Fatima, G. R., Malik, K., Muqadas, A., \& Fazal-ur-Rehman, M. (2019). Scope of Nanotechnology in Cosmetics: Dermatology and Skin Care Products. Journal of Medicinal and Chemical Sciences, 2, 9-16.

Hu, F. L., Bíliková, K., Casabianca, H., Daniele, G., Salmen Espindola, F., Feng, M., \& Li, L. (2019). Standard methods for Apis mellifera royal jelly research. Journal of Apicultural Research, 58(2), 1-68.

Ighodaro, O. M., \& Akinloye, O. A. (2018). First line defence antioxidants-superoxide dismutase (SOD), catalase (CAT) and glutathione peroxidase (GPX): Their fundamental role in the entire antioxidant defence grid. Alexandria Journal of Medicine, 54(4), 287-293.

Jacquemin, G., Margiotta, D., Kasahara, A., Bassoy, E. Y., Walch, M., Thiery, J., Lieberman J., \& Martinvalet, D. (2015). Granzyme B-induced mitochondrial ROS are required for apoptosis. Cell Death and Differentiation, 22(5), 862-874. https://doi.org/10.1038/cdd.2014.180

Jelic, M. D., Mandic, A. D., Maricic, S. M., \& Srdjenovic, B. U. (2021). Oxidative stress and its role in cancer. Journal of Cancer Research and Therapeutics, 17, 22-28.

Kluck, R. M., Bossy-Wetzel, E., Green, D. R., \& Newmeyer, D. D. (1997). The release of cytochrome c from mitochondria: a primary site for Bcl-2 regulation of apoptosis. Science, 275(5303), 1132-1136.

Kocot, J., Kiełczykowska, M., Luchowska-Kocot, D., Kurzepa, J., \& Musik, I. (2018). Antioxidant potential of propolis, bee pollen, and royal jelly: possible medical application. Oxidative Medicine and Cellular Longevity, 7074209. 
Kolayli, S., Sahin, H., Can, Z., Yildiz, O., Malkoc, M., \& Asadov, A. (2016). A member of complementary medicinal food: anatolian royal jellies, their chemical compositions, and antioxidant properties. Journal of Evidence-Based Complementary and Alternative Medicine, 21(4), 43-48.

Kucukler, S., Benzer, F., Yildirim, S., Gur, C., Kandemir, F. M., Bengu, A. S., \& Dortbudak, M. B. (2021). Protective effects of chrysin against oxidative stress and inflammation induced by lead acetate in rat kidneys: a biochemical and histopathological approach. Biological Trace Element Research, 199(4), 1501-1514.

Kucukler, S., Darendelioğlu, E., Caglayan, C., Ayna, A., Yıldıım, S., \& Kandemir, F. M. (2020). Zingerone attenuates vancomycin-induced hepatotoxicity in rats through regulation of oxidative stress, inflammation and apoptosis. Life Sciences, 259, 118382.

Liu, J. R., Yang, Y. C., Shi, L. S., \& Peng, C. C. (2008). Antioxidant properties of royal jelly associated with larval age and time of harvest. Journal of Agricultural and Food Chemistry, 56(23), 11447-11452.

Louis, C. U., \& Shohet, J. M. (2015). Neuroblastoma: molecular pathogenesis and therapy. Annual Review of Medicine, 66, 49-63.

Malka, O., Karunker, I., Yeheskel, A., Morin, S., \& Hefetz, A. (2009). The gene road to royalty-differential expression of hydroxylating genes in the mandibular glands of the honeybee. The FEBS Journal, 276(19), 5481-5490.

Maris, J. M. (2010). Recent advances in neuroblastoma. New England Journal of Medicine, 362(23), 2202-2211.

Melliou, E., \& Chinou, I. (2005). Chemistry and bioactivity of royal jelly from Greece. Journal of Agricultural and Food Chemistry, 53(23), 8987-8992.

Miyata, Y., \& Sakai, H. (2018). Anti-cancer and protective effects of royal jelly for therapy-induced toxicities in malignancies. International Journal of Molecular Sciences, 19(10), 3270.

Nakajima, Y., Tsuruma, K., Shimazawa, M., Mishima, S., \& Hara, H. (2009). Comparison of bee products based on assays of antioxidant capacities. BMC Complementary and Alternative Medicine, 9(1), 4-13.

Özbolat, S. N., \& Ayna, A. (2021). Chrysin suppresses HT-29 cell death induced by diclofenac through apoptosis and oxidative damage. Nutrition and Cancer, 73(8), 1419-1428.

Pan, Y., Rong, Y., You, M., Ma, Q., Chen, M., \& Hu, F. (2019). Royal jelly causes hypotension and vasodilation induced by increasing nitric oxide production. Food Science and Nutrition, 7(4), 1361-1370.

Park, M. J., Kim, B. Y., Park, H. G., Deng, Y., Yoon, H. J., Choi, Y. S., \& Jin, B. R. (2019). Major royal jelly protein 2 acts as an antimicrobial agent and antioxidant in royal jelly. Journal of Asia-Pacific Entomology, 22(3), 684689.

Pasupuleti, V. R., Sammugam, L., Ramesh, N., \& Gan, S. H. (2017). Honey, propolis, and royal jelly: a comprehensive review of their biological actions and health benefits. Oxidative Medicine and Cellular Longevity, 1259510.

Pfeffer, C. M., \& Singh, A. T. (2018). Apoptosis: a target for anticancer therapy. International Journal of Molecular Sciences, 19(2), 448-457.

Porta, C., Levy, A., Hawkins, R., Castellano, D., Bellmunt, J., Nathan, P., \& Vekeman, F. (2014). Impact of adverse events, treatment modifications, and dose intensity on survival among patients with advanced renal 
cell carcinoma treated with first-line sunitinib: a medical chart review across ten centers in five European countries. Cancer Medicine, 3(6), 1517-1526.

Premratanachai, P., \& Chanchao, C. (2014). Review of the anticancer activities of bee products. Asian Pacific Journal of Tropical Biomedicine, 4(5), 337-344.

Ramadan, M. F., \& Al-Ghamdi, A. (2012). Bioactive compounds and health-promoting properties of royal jelly: A review. Journal of Functional Foods, 4(1), 39-52.

Ramanathan, A. N. K. G., Nair, A. J., \& Sugunan, V. S. (2018). A review on Royal Jelly proteins and peptides. Journal of Functional Foods, 44, 255-264.

Rossé, T., Olivier, R., Monney, L., Rager, M., Conus, S., Fellay, I.,\& Borner, C. (1998). Bcl-2 prolongs cell survival after Bax-induced release of cytochrome c. Nature, 391(6666), 496.

Sabatini, A. G., Marcazzan, G. L., Caboni, M. F., Bogdanov, S., \& Almeida-Muradian, L. B. D. (2009). Quality and standardisation of royal jelly. Journal of ApiProduct and ApiMedical Science, 1(1), 1-6.

Silici, S. (2019). Honeybee Products and Apitherapy. Turkish Journal of Agriculture-Food Science and Technology, 7(9), 1249-1262.

Viuda-Martos, M., Ruiz-Navajas, Y., Fernández-López, J., \& Pérez-Álvarez, J. A. (2008). Functional properties of honey, propolis, and royal jelly. Journal of Food Science, 73(9), 117-124.

Wang, I. K., Lin-Shiau, S. Y., \& Lin, J. K. (1999). Induction of apoptosis by apigenin and related flavonoids through cytochrome $c$ release and activation of caspase-9 and caspase-3 in leukaemia HL-60 cells. European Journal of Cancer, 35(10), 1517-1525.

Yanagita, M., Kojima, Y., Mori, K., Yamada, S., \& Murakami, S. (2011). Osteoinductive and anti-inflammatory effect of royal jelly on periodontal ligament cells. Biomedical Research, 32(4), 285-291.

Yang, J., Liu, X., Bhalla, K., Kim, C. N., Ibrado, A. M., Cai, J., \& Wang, X. (1997). Prevention of apoptosis by Bcl2: release of cytochrome c from mitochondria blocked. Science, 275(5303), 1129-1132.

Yeung, Y. T., \& Argüelles, S. (2019). Bee Products: Royal Jelly and Propolis. In: Nonvitamin and Nonmineral Nutritional Supplements. Academic Press: 475-448.

Yin, L., Han, H., Zheng, X., Wang, G., Li, Y., \& Wang, W. (2019). Flavonoids analysis and antioxidant, antimicrobial, and anti-inflammatory activities of crude and purified extracts from Veronicastrum latifolium. Industrial Crops and Products, 137, 652-661. 